\title{
A case study of cut marks on camelid bones from the El Palacio site in the northern highlands of Peru: implication of butchering activities
}

\author{
Hiroki SEIKE ${ }^{1 *}$, Shinya WATANABE ${ }^{2}$ \\ ${ }^{1}$ Department of Anatomy, St. Marianna University School of Medicine, Kawasaki, Kanagawa 216-8511, Japan \\ ${ }^{2}$ Department of Anthropology, Nanzan University, Nagoya, Aichi 466-8673, Japan
}

Received 3 April 2021; accepted 29 April 2021

\begin{abstract}
South American camelids, which were domesticated in the Central Andes, have been emphasized for their secondary uses (e.g. llamas as pack animals and alpacas for their wool). In modern pastoral societies the use of mature animals for meat is not efficient. However, it is interesting that cut marks have often been found on archaeological animal bones. This study aimed to describe butchering of camelids through macroscopic observation of cut marks in the Middle Horizon period, during the Wari Empire (600-1000 CE), when the use of camelids reached its peak, and to test whether these activities are consistent with ethnoarchaeological and ethnographic findings. The materials used here are camelid bones with cut marks from El Palacio in the northern highlands of Peru. They were assigned to Middle Cajamarca Phases B and C, and a part of the Late Cajamarca Phase (800-1000 CE). In this study, cut marks on animal bones were observed by macroscopy, and analyses were focused on their distribution, frequencies, and direction. Cut marks on camelid bones from El Palacio were observed over the entire body, suggesting that these marks were caused by dismembering, skinning, and extraction of meat, fat, and marrow. The frequencies of cut marks on camelid bones at El Palacio was 1.3\%, lower than that in the Formative Period. This lower frequency might have been caused by more fragmented bones in the former. Furthermore, it is possible that the use of secondary products was emphasized at El Palacio. Cut marks were concentrated on the ventral side of each bone. This can be attributed to the butchering procedure described from ethnoarchaeology and ethnography, in which animal was turned on its back for dismemberment and removal of its internal organs from the ventral side, being careful not to soil the earth for ritual considerations.
\end{abstract}

Key words: Peru, camelids, Wari, cut marks, butchering activities

\section{Introduction}

\section{Historical background}

Parts of Peru and Bolivia form the Central Andean Region. This region consists of three broad sections, namely (from west to east), the Costa (coastal region), the Sierra (highland region), and the Montaña (eastern jungle region) (Pulgar Vidal, 1987). The Costa consists of an arid plain scored by 50 rivers of various sizes, flowing from the western slopes of the Andes into the Pacific (Seki, 2017). The region also has a number of oases located along valleys, from which the Andean civilization developed (Seki, 2017). The Sierra, which rises to $6000 \mathrm{~m}$ above sea level, is subdivided into five ecoregions: the Yunga, the Quechua, the

\footnotetext{
* Correspondence to: Hiroki Seike, Department of Anatomy, St. Marianna University School of Medicine, 2-16-1 Sugao, Miyamae Ward, Kawasaki City, Kanagawa 216-8511, Japan.

E-mail: hseike@marianna-u.ac.jp

Published online 22 July 2021

in J-STAGE (www.jstage.jst.go.jp) DOI: 10.1537/ase.210429
}

Suni, the Puna, and the Janca (Seki, 2017). The Yunga ('warm lands') is a warm and dry region on the lower slopes of the Andes between 500 and $2300 \mathrm{~m}$ above sea level (Seki, 2017). The Quechua ('high valleys'), distributed between 2300 and $3500 \mathrm{~m}$ above sea level, is a cooler region consisting of a mountain basin (Seki, 2017). This region was home to the Wari and Inca. It is also the location of El Palacio, the target region of the present study. The Suni, distributed between 3500 and $4000 \mathrm{~m}$ above sea level, is a cold zone (Seki, 2017). Between 4000 and $4800 \mathrm{~m}$ above sea level, the Puna ('mountain top') consists of a grassy plateau (Seki, 2017). These grasslands are inhabited by llamas and alpacas, which are well adapted to highland environments (Seki, 2017). Rising over $4800 \mathrm{~m}$ above sea level, the Janca ('white') consists of snow-covered peaks uninhabitable by humans (Seki, 2017). As these examples illustrate, the ecology of the Andes varies greatly with altitude, but land suitable for human use is limited. In addition, human mobility has been restricted by the sizeable elevation extremes and vastness of the coastal desert region.

The Andean people domesticated camelids (Camelidae). 
As well as rearing them for meat, they used them as pack animals. This practice led to active interregional exchanges. In this way, the domestication of camelids formed the starting point for the Andean civilizations.

Two species of wild camelid remain extant in South America today: the guanaco (Lama guanicoe) and vicuña (Vicugna vicugna). Modern genetics suggest that llamas are the domesticated descendants of the guanaco, and alpacas the domesticated descendants of the vicuña (Kadwell et al., 2001; Marín et al., 2006). The llama (Lama glama) is suited for grazing on dry pastures and can thrive and breed at low altitudes (Torres, 1992; Inamura, 1995). Llamas are often used as pack animals, and their robust wool and hide are used to make leather straps and packs for transporting goods (Inamura, 1995). The alpaca (Lama pacos/Vicugna pacos) is smaller than the llama, and its wool has a better overall texture (Torres, 1992; Inamura, 1995). As such, alpaca fiber is used to make woven fabrics (Torres, 1992; Inamura, 1995). The main sources of protein they provide are flesh and blood (Inamura, 1995). However, to maintain livestock populations, the animals are only slaughtered at certain times of the year, such as during festivals (Inamura, 1995, 2007).

Both species of South American camelids started being domesticated in the Junín Plateau (a region in the central highlands of Peru) around 4000 BCE (Wheeler, 1984). As evidence of this domestication, Wheeler (1984) cited the findings that the camelid population in the Telarmachay rock-shelter increased to comprise more than $80 \%$ of the total fauna of the area, the indications of anthropogenic modification in excavated bones, and that the population of camelid calves increased by more than $60 \%$ as a proportion of the total age profile. Wheeler (1984) also noted that as a result of domestication, alpacas have unusual incisors (e.g. she noted the lack of enamel on the lingual surface), making it possible to distinguish them from wild vicuñas.

Thereafter, the camelid population increased as a proportion of the total fauna, with the camelid distribution zone expanding in all directions from the Junín Plateau (Wing, 1986). This development reflected the domestication of camelids on the plateau and suggests that camelid use was becoming increasingly important to human populations in the areas around it. Camelids started appearing in the northern highlands of Peru around 800 BCE (Uzawa, 2007). This development can be traced back to the northward camelid propagation from the Junín Plateau (Uzawa, 2007). Given that the northern highlands of Peru have no high mountain ranges and lie outside the natural distribution of camelids, the camelid bones excavated in this region would have been from domesticated animals (Uzawa, 2007). In recent years, data indicating the domestication of camelids outside the Central Andes have been presented. In the South Central Andes, namely northwestern Argentina and northern Chile, intensive use of camelids, changes in morphological characteristics, and contextual evidence such as corrals and penning indicate that domestication proceeded in parallel with Central Andes in this region by 2500-2000 BCE (Goñalons and Yacobaccio, 2006).

\section{Previous studies of camelid utilization at the sites of Wari culture}

The indigenous culture of the northern highlands of Peru was the Cajamarca. Following its Formative Period, the Cajamarca flourished from $50 \mathrm{BCE}$ to $1532 \mathrm{CE}$. The use of camelids became established among the Cajamarca (Shimada, 1982, 1985). The Wari was an indigenous culture based in the southern highlands of Peru, and flourished there from 600 to $1000 \mathrm{CE}$. During the eighth century, the Wari built a political center that became known as El Palacio, located in the Cajamarca region. There have been no studies on the use of camelids by the Wari in the northern highlands of Peru, but Rosenfeld $(2011,2012)$ examined the use of camelids in the Wari's main homeland. Rosenfeld (2011, 2012) examined animal remains from a site in the heart of the Wari culture: the Conchopata site in the Ayacucho Valley. She also examined samples from two sites on the periphery of the culture: the Cotocotuyoc and Chokepukio sites in Cuzco Valley. At the Conchopata site, there was a largely equal share between camelids and Andes guinea pigs (known as cuy), but at the two Cuzco sites, camelids were preferred (Rosenfeld, 2011, 2012).

Similar research was conducted on samples from the center of the Tiwanaku culture of the Bolivian highlands, which was contemporaneous with the Wari (Webster and Janusek, 2003). These studies also indicated a preference for camelids (Webster and Janusek, 2003). These findings imply that as the camelid distribution expanded, human communities on the distribution zone's peripheries developed an even greater preference for camelids (Webster and Janusek, 2003).

In both the Wari and Tiwanaku societies, leaders displayed their wealth by sacrificing animals and serving chicha (maize beer) and camelid meat at feasts (Rosenfeld, 2011, 2012; Webster and Janusek, 2003). In this way, camelids played an important role in solidifying and maintaining power relations (Rosenfeld, 2011, 2012; Webster and Janusek, 2003). The Wari used camelids actively. Therefore, it would be valuable to obtain data on how the Wari used camelids when such use was at its peak.

\section{Traditional butchering procedure}

Because pre-Hispanic Andean civilizations had no writing system, they left no written records of their methods for butchering camelids. However, some Spanish conquistadors, who conquered the Inca in the sixteenth century, and some indigenous writers, recorded the butchery techniques in various chronicles of Peru. One example of a Peruvian chronicle was Felipe Guaman Poma de Ayala's 1615 work El primer nueva crónica y buen gobierno (The First New Chronicle and Good Government), which includes an illustration and textual description of a llama being slaughtered (Guaman Poma de Ayala, 1980 [1615]). It shows a man thrusting his right hand into the llama's abdomen from the side to wrench out its heart (Guaman Poma de Ayala, 1980 [1615]).

This butchery technique is still practiced by Andean herders today. The widespread practice of ch'illa (associated with abdominal incision) in the Cuzco region shown by Miller (1979) matched that depicted in Guaman Poma de 
Ayala's illustration (Guaman Poma de Ayala, 1980 [1615]).

Similarly, Inamura (1995) cited the same illustration and related it to the slaughtering practices observed during fieldwork. Thus, Inca butchery techniques of the pre-Hispanic period, as depicted in the Peruvian chronicles, match those of contemporary Andean herders. However, less is known about camelid butchery in pre-Inca times. As such, we wanted to obtain insights into this matter.

\section{Purposes of this study}

Prior to the Spanish conquest in the sixteenth century, the Andean peoples had an entirely indigenous culture- not one derived from African, Eurasian, or any other civilization. Animal farming was no exception: after domesticating camelids, the Andean civilizations developed a unique pastoralist culture. The Andean civilizations underwent a major transformation with the spread of Christianity by the Spanish conquistadors. Thus, a question arises regarding the depictions of Incan camelid butchery and rituals in contemporary ethnographies and in sixteenth-century Spanish accounts: how consistent are these depictions with actual animal usage from earlier times?

The purpose of this study was to determine whether butchery techniques for domesticated camelids as practiced by the Wari culture, which represented the high watermark of pre-Hispanic camelid use, are consistent with the descriptions in ethnoarchaeological and ethnographic case studies. To this end, we macroscopically inspected cut marks on camelid bones from the El Palacio site in the northern highlands of Peru.

The samples analyzed were excavated from El Palacio, a Wari site in the northern highlands of Peru. First, we discuss those bones that bear cut marks: for these cases, we describe the locations and distribution of the marks. Next, we give the estimated frequencies of cut marks among the bone samples and compare these estimates with the literature. In this way, we reconstruct how domesticated camelids were used by the Wari and verify whether such usage is consistent with the butchery techniques or slaughter rituals depicted in ethnoarchaeological reports, ethnographies, and Peruvian chronicles.

\section{Materials}

Found at an altitude of $2750 \mathrm{~m}$ above sea level, the El Palacio archaeological site is located within Miraflores village, in the department of Cajamarca in the northern highlands of Peru (Figure 1). From 1960, it was supposed that this site pertained to Wari culture (600-1000 CE), and we carried out the first excavations at El Palacio in 2008; additional excavations were conducted in 2010 and 2012. We have confirmed that this site was an administrative center of the Wari Empire that developed during the Middle Horizon (700-1000 CE) from its capital Huari, located in the department of Ayacucho, in the southern part of the central highlands of Peru. The Wari Empire is considered a prototype of the later Inca Empire because of the distribution pattern of administrative centers, etc. From the Cajamarca Valley the Wari people could proceed to the north coast where were located San José de Moro and Santa Rosa de Pucalá, which present clear evidence of Wari culture.

El Palacio was occupied during 800-1000 CE, which corresponds to Middle Cajamarca Phases B and C, and a part of the Late Cajamarca Phase according to the Cajamarca Valley

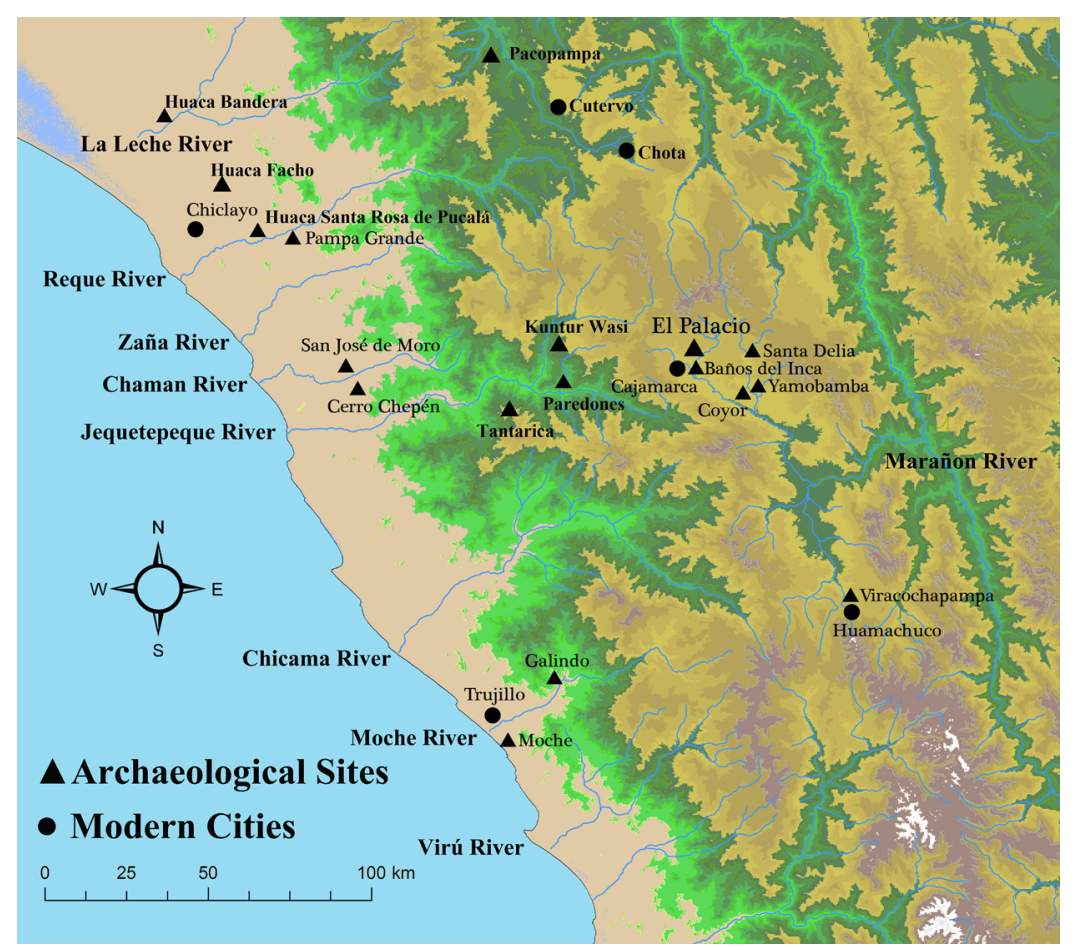

Figure 1. Map of Peru showing the location of the El Palacio site. $\boldsymbol{\Lambda}$, Archaeological site; $\bullet$, modern city. 


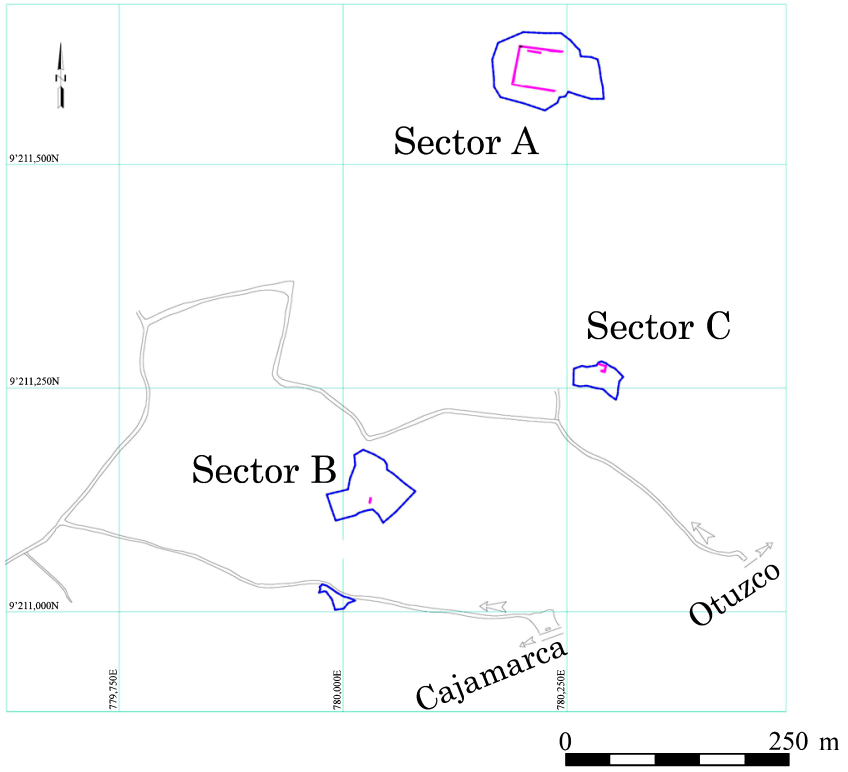

Figure 2. Location of the excavation area at the El Palacio site.

chronology. This site extends more than 100 ha and is located at the foot of Kolguitin Hill (Figure 2).

At the northern extremity of this site (Sector A) lies a rectangular building, measuring approximately $60 \mathrm{~m} \times 45 \mathrm{~m}$ in size, which is called 'El Palacio' by the local people. This building was abandoned in the process of construction and corresponds to the first part of the Late Cajamarca Phase. The main part of the site, Sector B, is located about $500 \mathrm{~m}$ south of sector A. We confirmed that this site extends to the slope of Kolguitin Hill where we excavated (Sector C).

It is important to note that construction activities were carried out in a new location without previous occupation. The site was constructed as Wari dominance began and was abandoned when Wari influence ended. The architectural style follows the Wari canon with a clear planification axis, differing from that of the Cajamarca culture. The evidence indicates that El Palacio was an administrative center of the Wari Empire.

At other administrative centers of the Wari Empire, such as Pikillacta or Viracochapampa, the architecture extended horizontally, while at El Palacio there were architectural renovations at the same place. The installation and renovation of subterranean canals within the administrative center present the northern highlands tradition that continued from the Formative Period. More than $2 \mathrm{~m}$ of accumulated soil that covered the previous architecture produced much material such as ceramics, lithics, and animal bones. More than $90 \%$ of the ceramic fragments were from the Cajamarca culture, apart from those of the Wari culture and the north coast. It is important to note that Wari ceramics are not limited to special contexts such as tombs or offerings but are ubiquitous in nearly every stratum.

At El Palacio, we discovered 30 tombs; nearly all of them were secondary burials. Many of them were found within the fill that covered the architecture. Tombs of a primary context were found at the wall base. Additionally, we encountered a

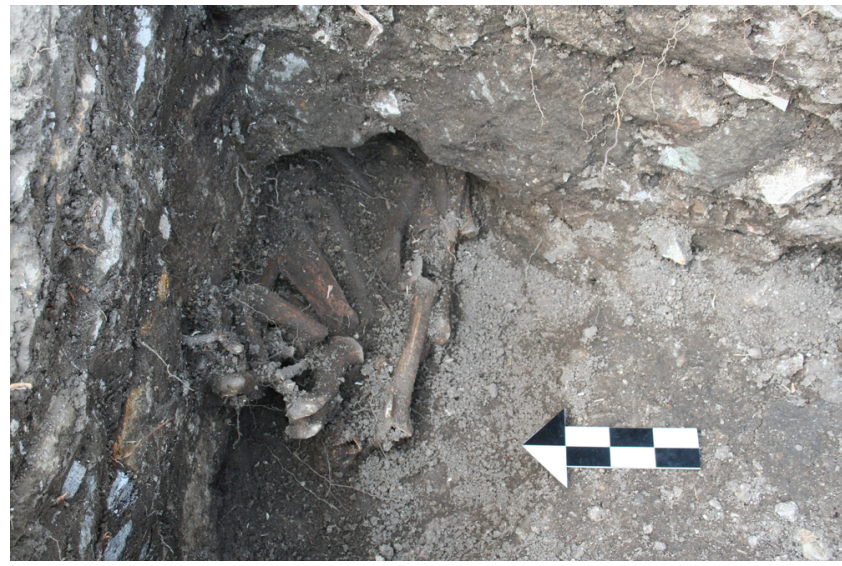

Figure 3. Camelid remains from the El Palacio site.

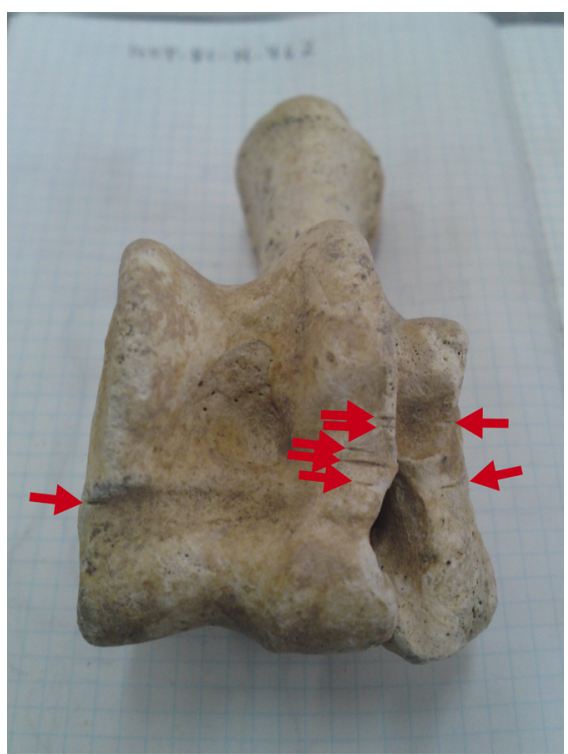

Figure 4. Cut marks on camelid bones from El Palacio (joint of left talus and left calcaneus, the same individual). Red arrows indicate cut marks.

semi-subterranean tomb that is supposed to have been for multiple mummies, although it was disturbed. We recovered about $125 \mathrm{~kg}$ of animal bones in the 2008 season, $305 \mathrm{~kg}$ in 2010, and $613 \mathrm{~kg}$ in 2012 (Figure 3). In this article, we analyze the material from the 2008 and 2010 seasons. All of the material is deposited at the Kuntur Wasi Museum located in the department of Cajamarca.

The specimens from the El Palacio site were examined from August to November 2011 at a research laboratory located in the Kuntur Wasi Museum. Data were collected on bones bearing cut marks created during butchery. The following items were recorded for these bone specimens: specimen number, geographic and stratigraphic position at the time of excavation, species of the animal, skeletal part, lateral position (left or right), and surface condition (e.g. locations of cut marks) (see Figure 4). Bones bearing cut marks were then sketched, and the details of different skeletal parts 
were recorded. The anatomical position of each bone bearing cut marks was then plotted on a diagram of a camelid skeleton. Next, the percentage of excavated camelid bones bearing cut marks was estimated. The sample consisted of camelid bones extracted from Sectors A and B of the El Palacio site. The number of identified specimens (NISP) of animal bones was 14243 , of which 12660 were camelid bones.

\section{Methods}

Bones were attributed to camelids by referring to a sample of a llama skeleton from Puno (in southern Peru), skeletal illustrations of South American camelids (Pacheco Torres et al., 1986), and sketches of llama skeletons from Department of Anatomy, Dokkyo Medical University (drawn by the first author). Bones were attributed to cervids (which belong to the Artiodactyla family) by referring to illustrations of Andean cervids (Altamirano, 1983) and to cervid bone specimens from Hitomi Hongo's laboratory at School of Advanced Sciences, the Graduate University for Advanced Studies (also drawn by the first author).

Cut marks were identified using a method established by Shipman (1981) and later developed by Lyman (1994). Using this method, cut marks were identified based on: (1) elongated grooves, (2) grooves that were V-shaped in cross-section, (3) short and frequent parallel marks running lengthways, and (4) a scarcity of shoulder effects or barbs (Shipman, 1981; Lyman, 1994).

In a study on caribou hunting among the Nunamiut in the Arctic, Binford (1981) demonstrated that cut marks in butchered caribou can be categorized as the result of dismembering, skinning, or filleting based on their location, frequency, and morphology. Building on Binford's findings, Moore (1989) examined the skeletal parts where traces of dismembering, skinning, or filleting are more likely to be clustered.

The present study adopted Binford and Moore's classification system and classified cut marks as the result of skinning, dismembering, or filleting based on their anatomical locations. Two other causes of bone marks were considered: bone marrow extraction and meat preservation. (1) The effects of dismembering tend to be observed on the long bone epiphysis, vertebrae, and hip bone (Moore, 1989). (2) The effects of skinning tend to be observed on the wrist, ankle, and nasal bones (Moore, 1989). (3) The effects of filleting tend to be observed on the tendon-bone enthesis (Moore, 1989). (4) The effects of meat preservation tend to be observed on the ribs and vertebrae, which have a low volume of bone marrow and tendons (Moore, 1989). (5) The effects of preparing for bone marrow extraction tend to be observed on the long bone shaft (Binford, 1978; Moore, 1989).

To verify butchery techniques for camelids, the cut marks were compared with modern-day llama butchery as observed by Miller (1979) and the first author. Miller observed the butchery of camelids in Tuqsa and Huaycho in southern highlands of Peru. In 2009, the first author observed the butchery of a llama in Puno (also in the southern highlands of Peru) as part of the process for producing a sample skeleton.

The minimal number of animal units (MAU) was em- ployed as a unit of measurement for frequency. The MAU is calculated by standardizing the minimum number of elements (MNE: an index number representing the minimum number of skeletal parts to account for the specimens representing that part) by the number of times the part occurs in the skeleton. For each skeletal part, the \%MAU was estimated, with 100 representing the maximum possible MAU for that part. The mandible was used in place of the skull because there tend to be many skull fragments because of its fragility. Hence, we did not show them as frequency by skeletal part.

Anatomical nomenclature was adopted from Pacheco Torres et al. (1986), Kato and Yamauchi (2003), and Matsui (2008).

\section{Results and Discussion}

To reconstruct the butchery, the distribution and frequencies of cut marks by skeletal part were recorded and compared with the literature.

\section{Locations of cut marks}

Figure 5 shows a chart of the skeleton of South American camelids indicating cut marks found on animal bones from El Palacio (red arrows). The cut marks can be seen distributed throughout the body. Cut marks were found as follows: (1) on the head: occipital bone; (2) on the forelimbs: proximal and distal humerus, proximal and distal radio-ulna, and proximal and distal metacarpals; (3) on the hind limbs: proximal and distal femur, proximal and distal tibia, tarsals including the talus and calcaneus, and proximal metatarsals; and (4) on the axial skeleton: atlas, third through seventh cervical vertebrae, lumbar vertebrae, sacral vertebrae, caudal vertebrae, and ribs (concentrated around the joints).

\section{Cut marks produced during dismemberment \\ Occipital and atlas}

Figure 6 shows the cut marks on the atlanto-occipital joint. The cut marks on the occiput posterior are shown in

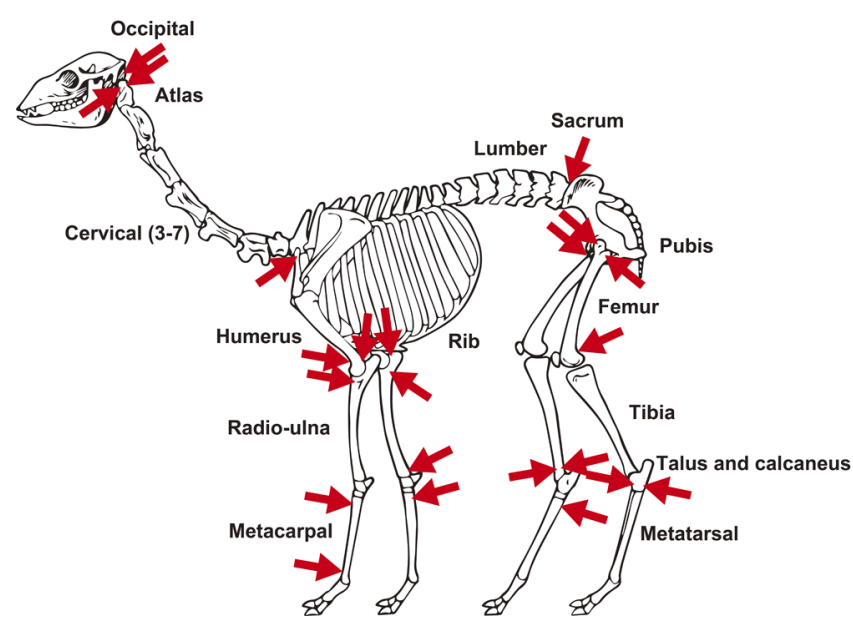

Figure 5. Location of cut marks on camelid bones excavated from the El Palacio site. Red arrows indicate cut marks. Camelid skeleton chart redrawn from Marcus et al. (1999). 


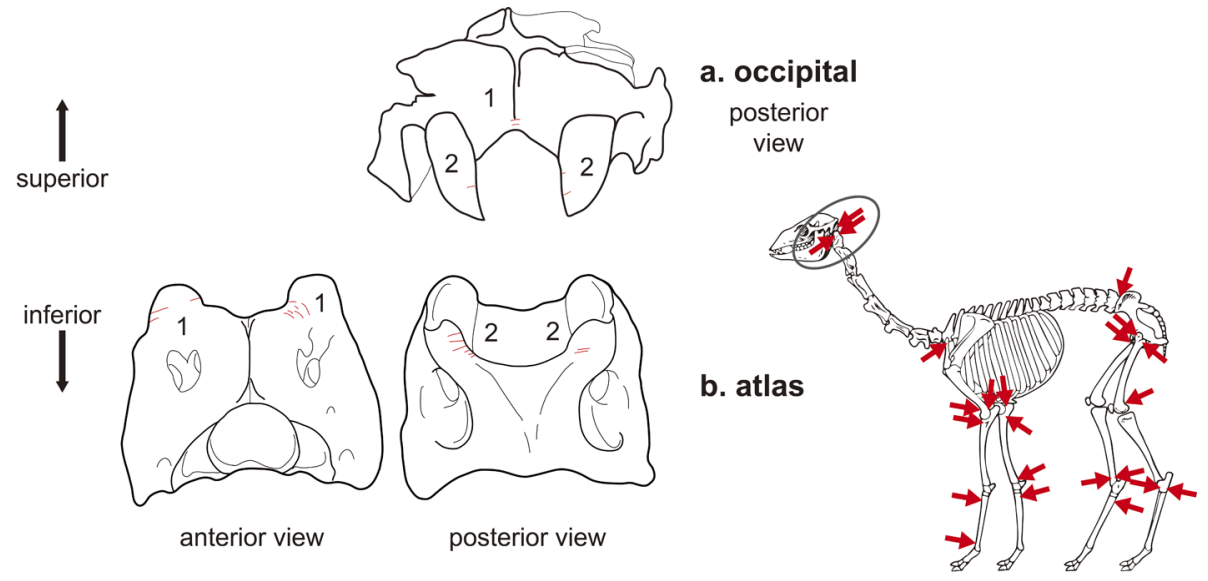

Figure 6. Dismembering cut marks (occipital and atlas). (a) Occipital: 1, enthesis of nuchal ligament; 2, occipital condyles. (b) Atlas: 1, 2, enthesis of nuchal ligament. Camelid skeleton chart redrawn from Marcus et al. (1999).

Figure $6 \mathrm{a}$ and those on the atlas in Figure $6 \mathrm{~b}$. Transverse cut marks appeared in the nuchal ligament enthesis (Figure 6a1). Such cut marks also appeared in the left and right occipital condyles (Figure 6a-2) and on the anterior and posterior surfaces of the left and right superior articular process (Figure $6 \mathrm{~b}-1, \mathrm{~b}-2)$.

Miller (1979) identified three modern-day Andean butchery techniques for camelids: the ventral throat slit, the dorsal stab, and the ch'illa. The ventral throat slit involves slitting the throat on the ventral side. The dorsal stab involves stabbing the neck on the dorsal side (Miller, 1979). The ch'illa is a traditional butchery technique that can be traced back to at least Inca times (Miller, 1979). This technique was recorded in the Peruvian chronicles (e.g. Guaman Poma de Ayala, 1980 [1615]). Miller (1979) noted that butchers would make an incision in the abdomen, thrust their hand inside, rip the diaphragm, and wrench out the heart. Because the head and neck would be removed during this operation, cut marks were likely to appear on the occipital bone or atlas (Miller, 1979). The head would be severed by cutting between the atlas and occipital bone, cleanly separating the head from the neck (Miller, 1979). Consequently, cut marks were likely to appear on the ventral sides of the atlas and occipital bone (Miller, 1979).

Thus, the cut marks observed on the occipital bone and atlas (Figure 6a-1, a-2, b-1) were likely the result of severing the head from the neck.

\section{Elbow joint}

Figure 7 shows cut marks on the elbow joint. On the right distal humerus, oblique (Figure 7a-1) and horizontal (Figure 7a-2) cut marks were observed on the lateral side of the lateral condyle. Horizontal cut marks were also seen on the medial margin of the coronoid fossa (Figure 7a-3). On the left distal humerus (Figure 7b), horizontal cut marks were seen on the bilateral margins of the posterior olecranon fossa (Figure 7b-1). On the right proximal radio-ulna (Figure 7c), cut marks were seen within the trochlear notch (Figure 7c-1) and on the coronoid process (Figure 7c-2). Horizontal cut marks were also seen on the olecranon (Figure 7c-3).
According to Miller (1979), the humerus would be severed from the radio-ulna by cutting the enthesis around the semilunar notch of the latter. Given this, the cut marks observed on the sample were probably formed by removing the elbow joint and separating the humerus from the radio-ulna. Cut marks were observed on the right proximal radio-ulna (Figure 7c-3), which correspond to the cut section 1 depicted by Miller (1979) in Figure 2-12 when the radio-ulna was cut into four pieces. They may have been the result of preparing meat cuts of a suitable size for consumption.

\section{Wrist and ankle joints}

Figure 8 shows cut marks on the tarsal joint. On the left talus, horizontal cut marks were observed on the lateral anterior surface (Figure 8a-1). On the left talus (Figure 8a), horizontal cut marks were seen on the lateral anterior surface (Figure 8a-1), and anterior-posterior cut marks were seen on the medial anterior surface (Figure 8a-2, a-3). On the right calcaneus, cut marks were observed on the anterior surface of the central calcaneus body (Figure 8b-1). On the left calcaneus, transverse cut marks were observed on the upper and lateral portions of the articular surface of the anterior talus (Figure 8b-2). Figure 8c shows the left talus and calcaneus of the same individual (Figure 8c-1).

Miller (1979) noted that the forelimbs would be dismembered by disjointing the carpal bones from the proximal ends of the metacarpal bones and that the hind limbs would be dismembered by disjointing the tarsal bones from such. In each case, the metacarpal bones would be bent forward (distally) so that they hung from the limb (Miller, 1979). For the hind limbs, Miller (1979) identified two techniques: (1) the talus (astragalus) and calcaneus, and the cuboid and scaphoid, were disjointed, with the talus (astragalus) and calcaneus still attached to the femur; and (2) the tarsal bones were disjointed from the metacarpal bones after attaching all the tarsal bones to the tibia.

Cut marks were observed on areas around the joints on the talus (astragalus) and calcaneus (Figure 8c-1) and on the proximal metacarpal bones (Figure 9-1, 9-2). These marks may have been the result of the two techniques described 


\section{a. Right distal humerus}

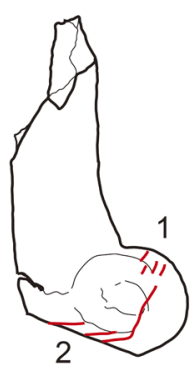

lateral view

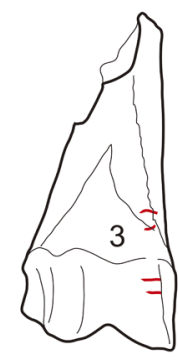

anterior view

\section{c. Right proximal radio-ulna}
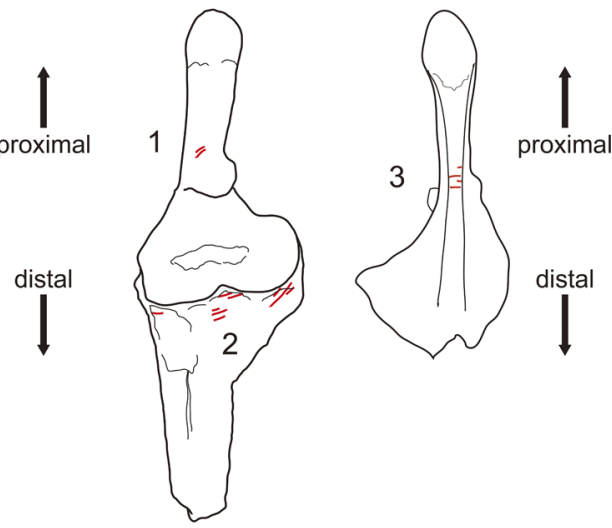

anterior view

posterior view

\section{b. Left distal humerus}
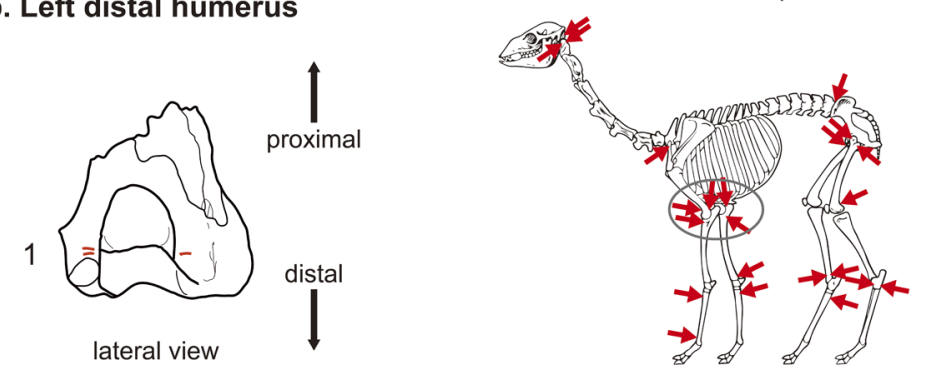

Figure 7. Dismembering cut marks (elbow joint). (a) Right distal humerus: 1, joint of ulnar collateral ligament; 2, insertion of triceps brachii muscle (long head and lateral head); 3 , insertion of long head of triceps brachii muscle. (b) Left distal humerus: 1, insertion of anconeus muscle. (c) Right proximal radio-ulna: 1, insertion of anconeus muscle; 2 , insertion of biceps brachii muscle and brachialis muscle; 3 , origin of flexor carpi ulnaris muscle (head of ulna). Camelid skeleton chart redrawn from Marcus et al. (1999).

a. Left talus

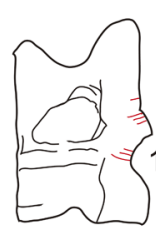

anterior view

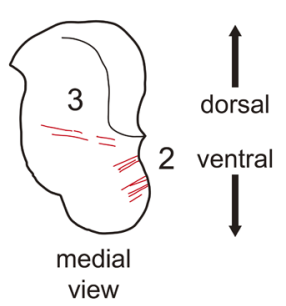

\section{b. Calcaneus}

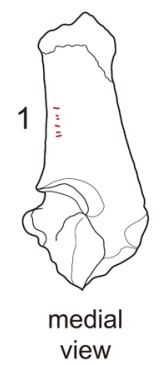

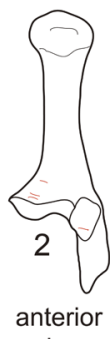

view

right

\section{c. Joint of left talus and left calcaneus}
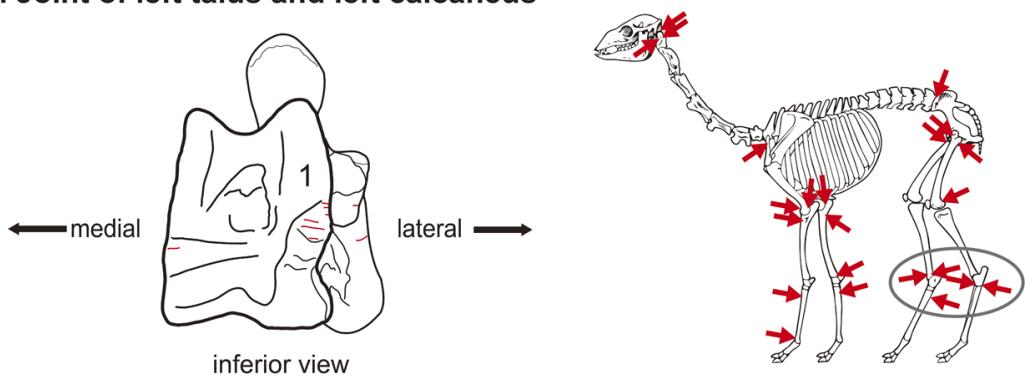

Figure 8. Dismembering cut marks (ankle joint). (a) Left talus: 1, enthesis of lateral collateral ligament; 2, 3, medial collateral ligament covered bone surface. (b) Left calcaneus and right calcaneus: 1, surface covered by calcaneal tendon over tuberosity of calcaneus; 2, enthesis of lateral collateral ligament. (c) Joint of left talus and left calcaneus: 1, enthesis of radial collateral ligament. Camelid skeleton chart redrawn from Marcus et al. (1999). 


\section{Left proximal metacarpal}
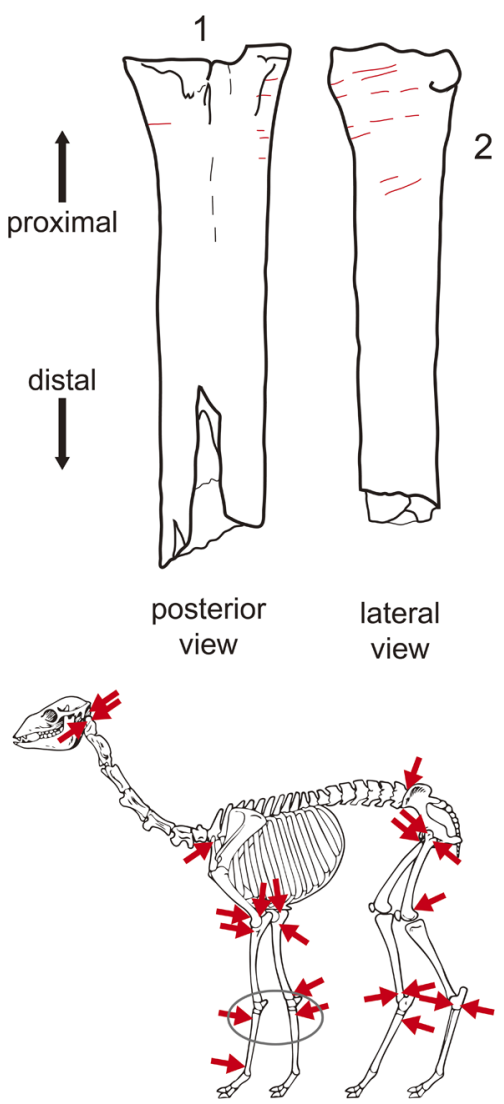

Figure 9. Skinning cut marks (left proximal metacarpal): 1, attachment of extensor carpi ulnaris muscle; 2 , tendinous attachment of extensor carpi radialis muscle. Camelid skeleton chart redrawn from Marcus et al. (1999).

above. In addition, Miller's description is consistent with what the first author observed during the production of a llama skeleton in Puno in summer 2009 (Figure 10).

\section{Pelvic joint}

Figure 11 shows cut marks on the pelvis. On the right
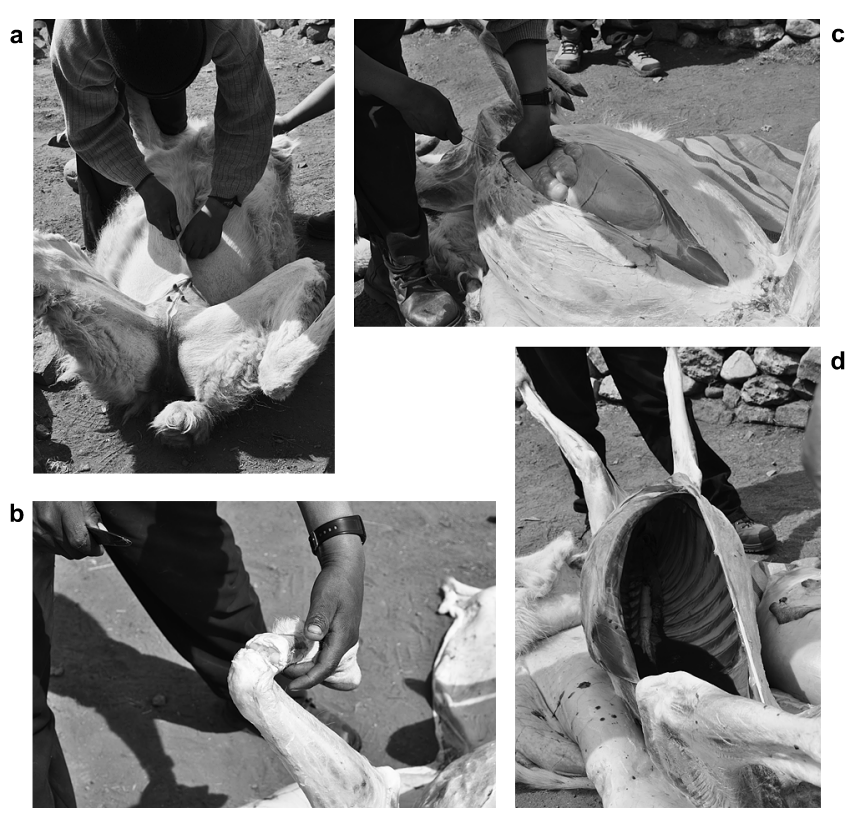

Figure 10. Butchering llama observed in Puno, Peru. (a) Skinning at the midline of the ventral side. (b) Dismembering carpometacarpal joints. (c) Removing internal organs from the ventral side. (d) Blood pooling within body cavity after removal of the internal organs. Photograph by Yoshifumi Sato.

pubis, anterior-posterior cut marks were seen on the lower acetabulum (Figure 11a-1). Figure 11b shows the cephalad side of the sacrum. On the right lateral side, there were cut marks in the medial and lateral directions. On the right sacrum, transverse cut marks were seen near the anterior articular process (Figure 11b-1).

According to Miller (1979), in the case of the hind limbs, the pubic symphysis was cut to disjoint the hip bone from the sacrum, and the hip bone was disjointed from the femur by cutting carefully between the head of the femur and acetabulum.

Therefore, the cut marks on the lower part of the acetabulum of the right pubic seen in El Palacio (Figure 11a-1) are thought to have been made when the acetabulum was separated from the femur.

\section{a. Right pubis}

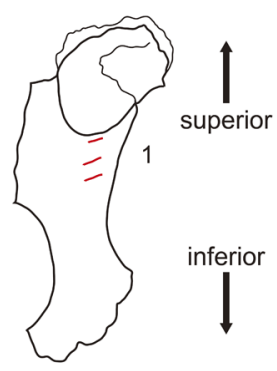

b. Sacrum

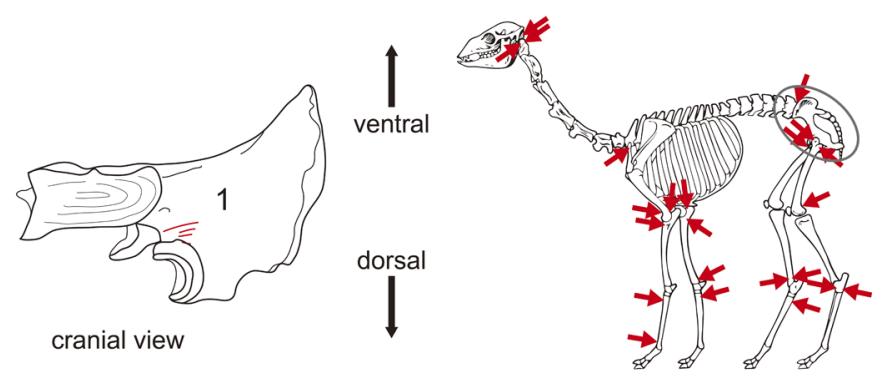

lateral view

Figure 11. Dismembering cut marks (pelvis). (a) Right pubis: 1, enthesis of pubofemoral ligament. (b) Sacrum: 1, enthesis of iliolumbar ligament and dorsal sacroiliac ligament. Camelid skeleton chart redrawn from Marcus et al. (1999). 


\section{Skinning cut marks at the left proximal metacarpal}

Figure 9 shows the left proximal metacarpal. Transverse cut marks were seen on both ends of the posterior surface of the left proximal metacarpal, especially on the medial side (Figure 9-1). Transverse cut marks were also seen over a wide area on the lateral surface of the proximal portion (Figure 9-2).

According to Moore (1989), skinning cut marks are most likely to appear on the anterior surfaces of the ulnar, central, and radial carpal bones; on the anterior surfaces of the central and fourth tarsal bones; and on the anterior surfaces of the premaxilla and maxilla. Given that these skinning marks span joints, they can be differentiated from dismembering marks (Moore, 1989).

Figure 9-1 shows the enthesis of the extensor carpi ulnaris muscle, and Figure 9-2 shows where the carpi radialis muscle adjoins the tendinous area. The flesh on the bone here would have been limited. During the llama dismemberment observed by the first author, the limbs were skinned down to the proximal metacarpal bones. Such skinning probably left marks on the metacarpal area because this area is less fleshy than other parts of the limbs. Therefore, the cut marks on the left proximal metacarpal from El Palacio are also considered to have been made during skinning.

\section{Filleting cut marks on left distal radio-ulna, left proximal, and distal femur}

At El Palacio, some cut marks were found in non-articular areas (Figure 12). On the left proximal femur, cut marks were found on the posterior surface of the greater trochanter (Figure 12a-1); on the left distal femur (Figure 12b-1), cut marks were found at both ends of the popliteal surface; and on the left distal radio-ulna, cut marks were found on both sides of the upper posterior surface (Figure 12c-1).

According to Miller (1979), the distal end of the radioulna was filleted with the tarsal bone still attached, and the tarsal bone was never removed during cooking. According to Moore (1989), cut marks appearing where the bone is connected to the muscles and tendons are the result of the muscles being pared off from the bone.

The cut marks on the left distal radio-ulna (Figure 12c-1) were concentrated on the insertion of the flexor digitorum superficialis muscle. The cut marks on the proximal left femur (Figure 12a-1) were located at the origin of the vastus lateralis muscle. The cut marks on the distal left femur (Figure 12b-1) were located at the origin of the gastrocnemius muscle and the flexor digitorum superficialis muscle.

\section{Cut marks related to $c h$ 'arki production}

Figure 13 shows cut marks on the spine and ribs. Oblique cut marks were observed on the dorsal and lateral surfaces of the anterior articular processes of the cervical vertebra (Figure 13a-1). Mediolateral cut marks were observed on the ventral aspect of the anterior articular process and the ventral aspect of the vertebral body of the lumbar vertebra (Figure 13b-1). They were parallel to each other. Cut marks were found on the lateral aspect of the left rib and on the neck of the rib at the base of the rib head, where it articulates with the thoracic vertebra (Figure 13c-1). Figure 13a-1 and b-1 show cut marks on the anterior articular process, and Fig-

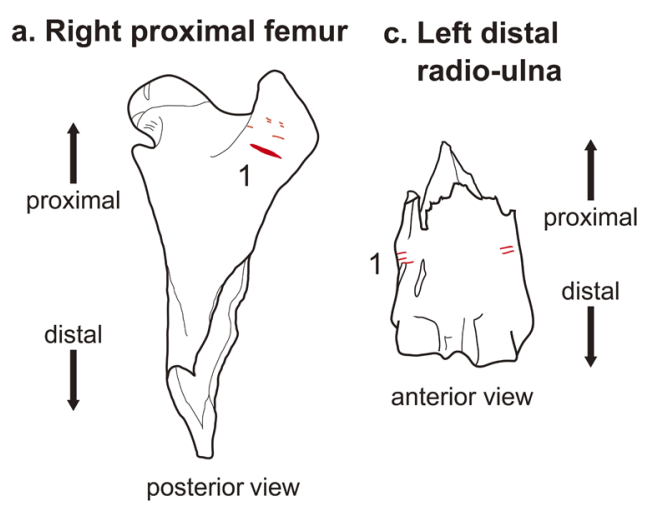

b. Left distal femur

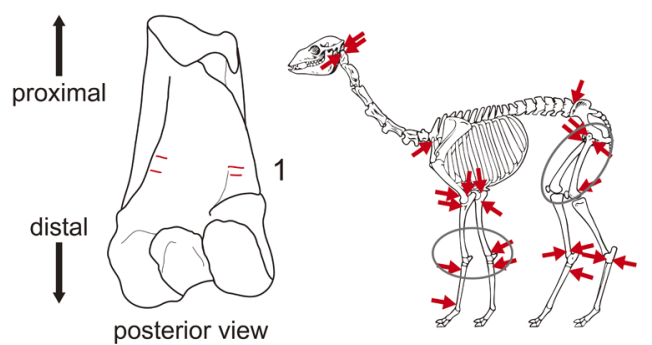

Figure 12. Filleting cut marks. (a) Right proximal femur: 1, origin of vastus lateralis muscle. (b) Left distal femur: 1, origins of gastrocnemius muscle and flexor digitorum superficialis muscle. (c) Left distal radio-ulna: 1, insertion of flexor digitorum superficialis muscle and flexor digitorum profundus muscle. Camelid skeleton chart redrawn from Marcus et al. (1999).

ure 13c-1 shows a mark near the articular surface of the rib.

At El Palacio, cut marks were found on the vertebrae, including the anterior articular fossa of the cervical vertebra (Figure 13a-1), the ventral side of the lumbar vertebral body (Figure 13b-1), and the anterior articular fossa of the sacrum (Figure 11b-1). According to Miller (1979), vertebrae were severed at the intervertebral joint and cut out by each bone. The lumbar vertebrae were prized for the tender flesh surrounding them, while the flesh around the cervical vertebrae was tougher, making it the hardest portion to separate (Miller, 1979). According to Moore (1989), the cut marks on the cervical and lumbar vertebrae were formed during the production of ch'arki, a type of Andean dried meat (Binford, 1978; Miller, 1979). The cut marks at El Palacio seem to have been made when the vertebrae were individually dismembered: the anterior articular fossa of the cervical vertebrae (Figure 13a-1), the ventral side of the lumbar vertebral body (Figure 13b-1), and the anterior articular fossa of the sacrum (Figure 11b-1). Miller (1979) noted that ch'arki was made in the Puna ecoregion since the process involved drying the meat in the hot sun and freezing it in the cold at night. The Quechua region would have been unsuited to the production of ch'arki. Miller and Burger (1995) suggested that the ch'arki made at the sites of a higher altitude than El Palacio (such as Chavín de Huántar) would have been sourced from camelids from a neighboring ecoregion, the plateau grasslands, and would have been made in that neighboring ecoregion before being brought to the site. As for El 
a. Cervical vertebra

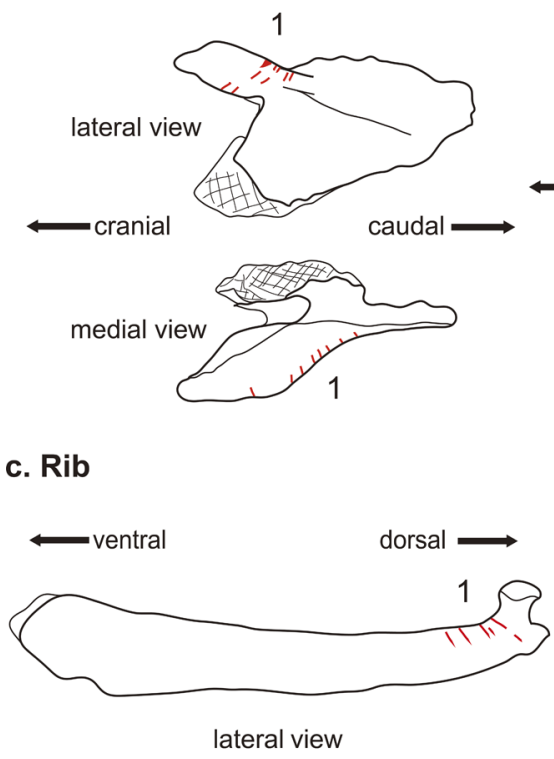

\section{b. Lumber vertebra}
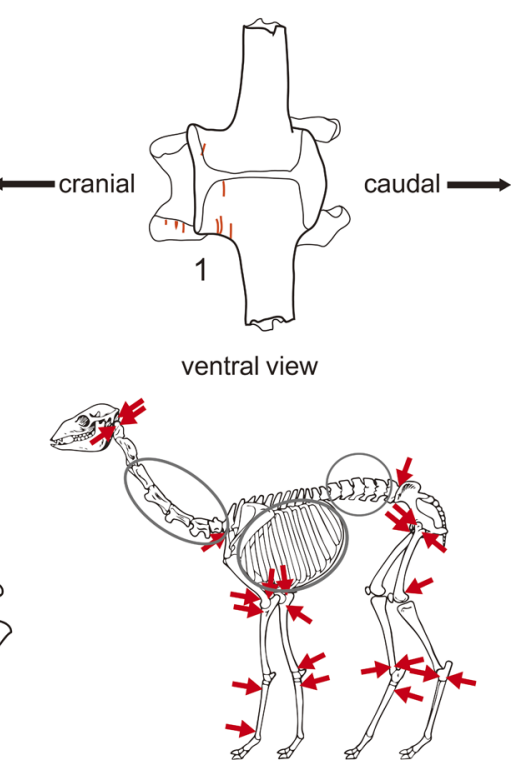

Figure 13. Cut marks related to ch'arki production. (a) Cervical vertebra: 1, anterior articular process. (b) Lumbar vertebra: 1, anterior articular process. (c) Rib: 1, cut marks related to dismemberment of the ribs and thoracic vertebrae. Camelid skeleton chart redrawn from Marcus et al. (1999).

Palacio, this site had relations with distant communities and was able to procure goods from a wide area. In this regard, it was a political center. The ch'arki consumed here was probably made in the Puna to the south or the neighboring grassland region.

Described below are the data on the appearance frequency by skeletal part that Miller and Burger cited as evidence for ch'arki trade. As a result of this trade between higher and lower regions, many non-fleshy parts such as the foot bones (metacarpal bones and phalanges) and skulls appeared in the Puna, where the ch'arki was made, while many leg bones (fleshy bones such as the humerus and femur) and axial bones appeared in lower regions (valleys and coastal areas), where $c h$ 'arki was consumed (Miller and Burger, 1995). The bones excavated at El Palacio were from all parts of the camelid (Table 1). In terms of frequency by skeletal part, leg and cranial elements were relatively abundant, suggesting a lack of the ch'arki effect (Figure 14).

The evidence suggests that the denizens of El Palacio, in addition to procuring ch'arki, obtained whole camelid carcasses, which would have been brought to the site in caravans (camel trains) or would have come from camelids reared in a neighboring grassland region. Thus, the lack of a discernible ch'arki effect may be because the cases where whole camelid carcasses were acquired overlaid cases of ch'arki consumption. Miller and Burger (1995) called this pattern the "kichwa zone mixed consumption pattern" (Miller and Burger, 1995: 29). Thus, the residents consumed both ch'arki and fresh meat.

Future efforts to identify the skeletal parts associated with ch'arki production by such means as isotope analysis should help pinpoint the regions where camelids were reared, which will contribute to the discussion on whether ch'arki was transported from distant sites.
Table 1. Cut marks on camelid bones from El Palacio (sectors A and $\mathrm{B}$ )

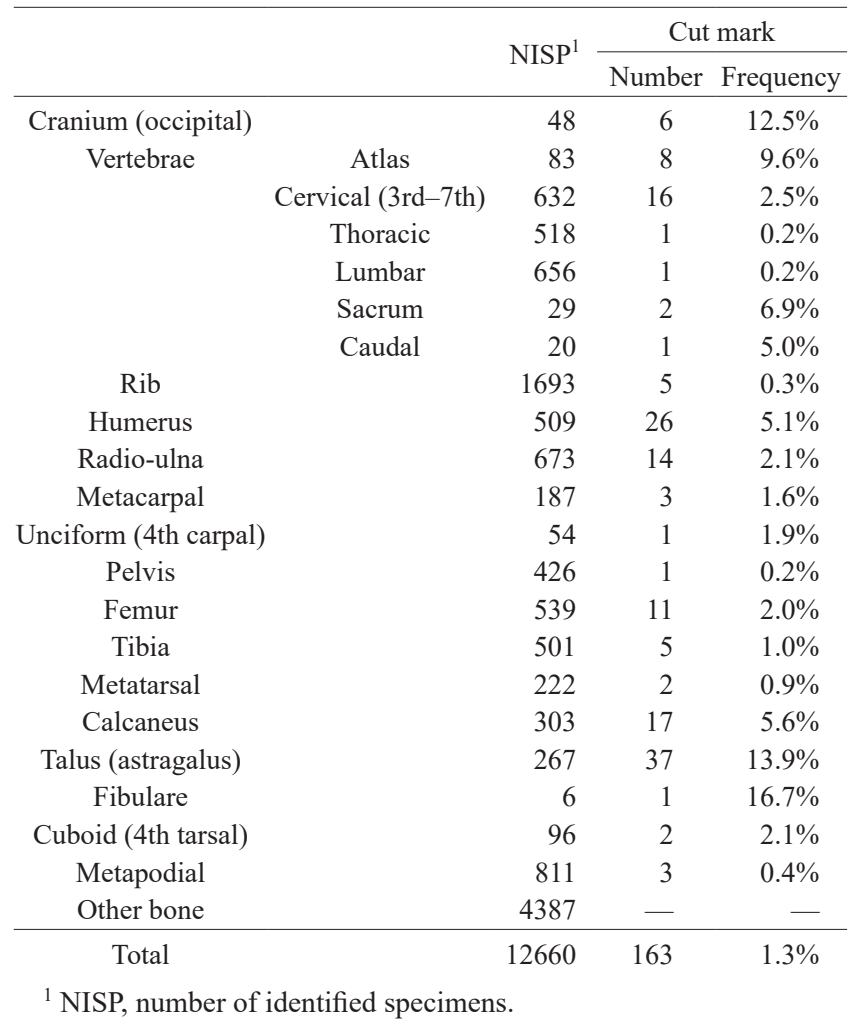

\section{Cut marks represent preparations for bone marrow extraction}

Figure 15 shows cut marks on the diaphysis of a limb 


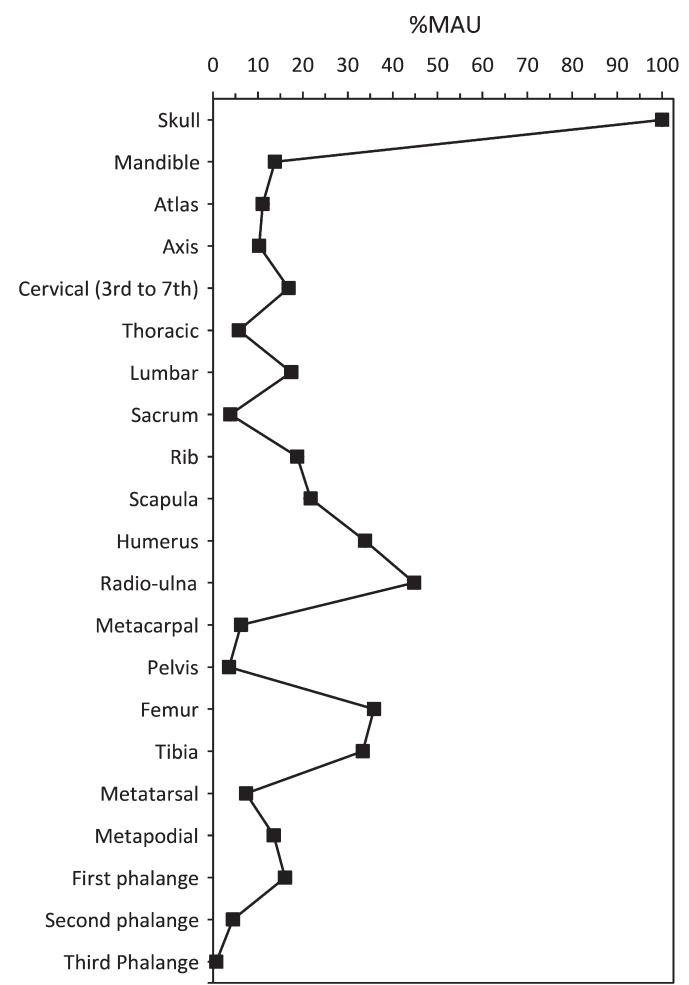

Figure 14. Percentage minimum animal units (\%MAU) of camelids from El Palacio shown by skeletal parts.

\section{a. Shaft of right femur}

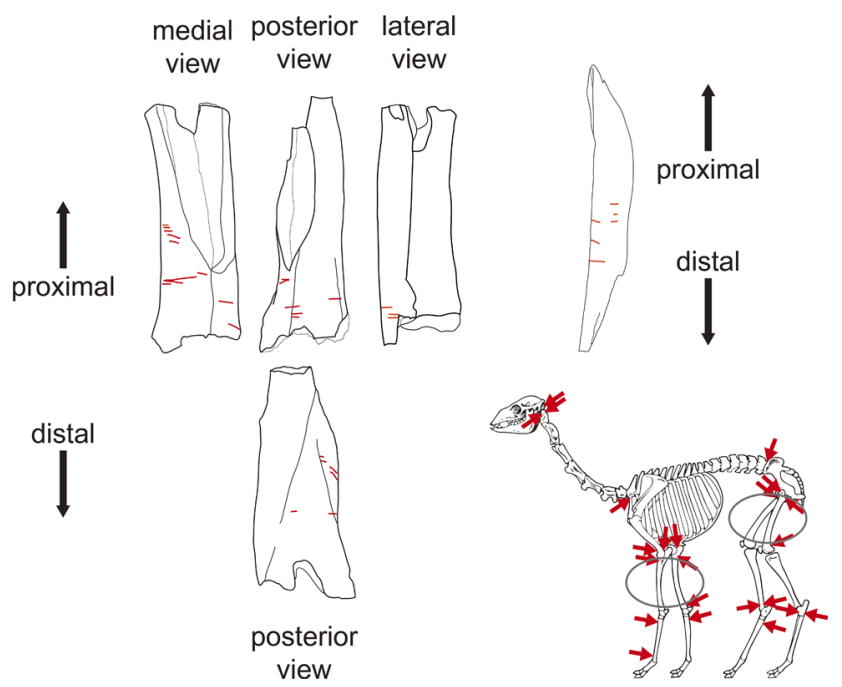

Figure 15. Cut marks representing preparation for bone marrow extraction. (a) Fragmented shaft of right femur. (b) Fragmented shaft of radio-ulna. We cannot determine the laterality and location due to poor preservation. Camelid skeleton chart redrawn from Marcus et al. (1999).

bone. On the shaft of the right femur, there were many transverse cut marks on the medial, lateral, and posterior surfaces (Figure 15a). On the shaft of radio-ulna unknown left and right sides, cut marks were seen in the transverse direction

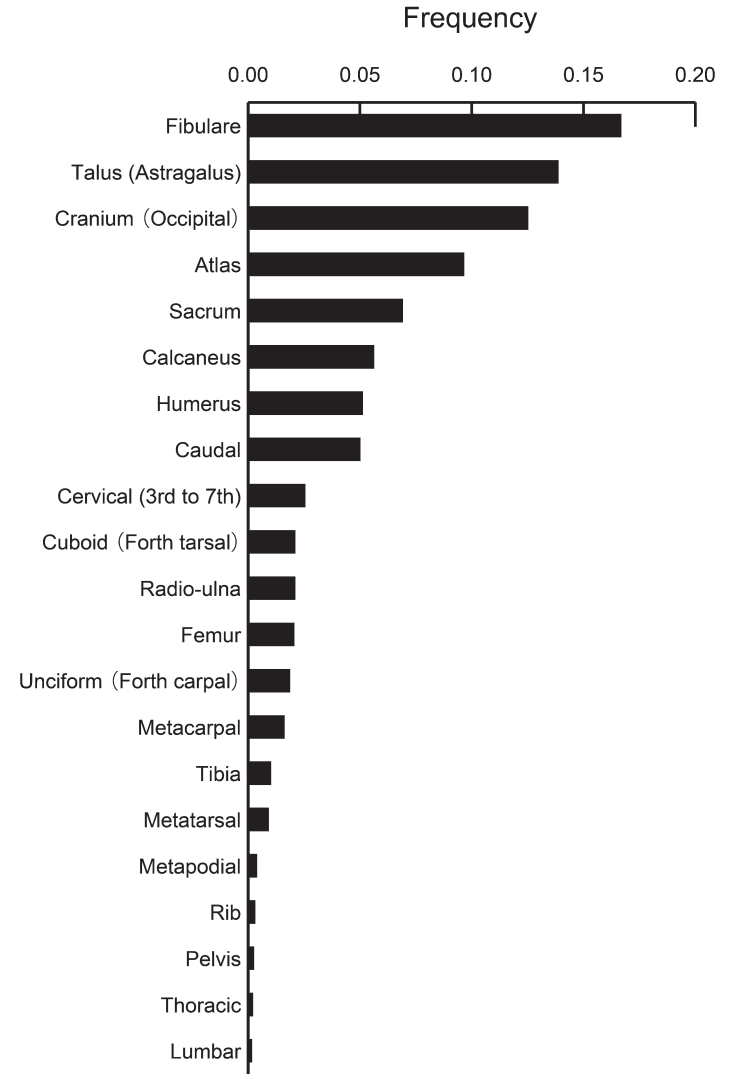

Figure 16. Frequencies of cut marks on camelid bones from El Palacio.

(Figure 15b).

Citing Binford's (1978) research on caribou hunters in the Arctic, Moore (1989) claimed that cut marks were made in the long bone shaft when bone marrow and grease were extracted. According to Binford (1978), the modern-day Nunamiut of Alaska, when extracting bone marrow from fresh caribou bones, scrape off (as carefully as possible) the remaining tendons and periosteum before breaking the bones. In his study of the Panaulauca site on the Junín Plateau (7700 BCE-1195 CE), Moore (1989) observed abundant cut marks on the surface of the long bone, which may have been the result of such an operation.

Similarly, cut marks on the diaphysis of the femur and radio-ulna (Figure 15a, b) at El Palacio seem to have been made during preparations for the removal of bone marrow and bone fat.

\section{Frequencies of cut marks}

Table 1 shows the frequencies of cut marks on each part of the camelid bones from the El Palacio site. The total number of camelid bones from El Palacio was 12660 by NISP, of which 163 had cut marks. The frequency of cut marks was $1.3 \%$ (Table 1). Cut marks were found most frequently on 37 talus $(13.8 \%), 8$ atlas $(12.5 \%), 27$ humerus $(5.1 \%), 17$ calcaneus $(5.6 \%), 11$ femur $(2.0 \%)$, and 14 radio-ulna $(2.1 \%)$ (Table 1, Figure 16).

According to Uzawa et al. (2021), who examined animal 
bones from the Pacopampa site from the Formative Period, the frequency of camelid cut marks at Pacopampa was 5.3\%. Sixty-seven bones exhibited cut marks out of 1253 camelid limb fragments from Pacopampa (Uzawa et al., 2021). On the other hand, 57 of 1479 deer fragments from Pacopampa exhibited cut marks, a frequency of 3.9\% (Uzawa et al., 2021). Regarding the camelid and cervid remains excavated at the Pacopampa site, Uzawa et al. (2021) claims that these animals were used in rituals, based on the fact that the selected animals were young and the parts selected were fleshy, and attributes the high frequency of cut marks to such use of the animals. Bones bearing cut marks accounted for $1.3 \%$ of the specimens from El Palacio, which is lower than the rate for the Artiodactyla assemblages at the Pacopampa site. While the possibility of observer error cannot be ruled out, this discrepancy may imply a difference in camelid use between the two sites. In general, camelids were reared for secondary products: llamas were typically used as pack animals and alpacas for their wool. To this end, herders would have tried to keep the animals alive for as long as possible. At the Kuntur Wasi site, the age profile is heavily biased toward young and aged animals, and mandibles of aged (10+ years) camelids were found (Uzawa, 2007). Uzawa (2007) also cited Inamura's (1995) ethnographic case study. Inamura (1995) found that for use in llama caravans, modern-day pastoralists select only mature and well-trained llamas, not those younger than two years. Uzawa (2007) concluded that the existence of the older camelids precludes the possibility that the age profile was geared toward meat production and suggested that the people of Kuntur Wasi used the camelids to transport resources.

El Palacio, likewise, yielded the teeth of old llamas. Also excavated were incisors with a morphology suggesting alpaca. Thus, the fact that cut mark frequency differs between El Palacio and Pacopampa (despite the two sites being in the same area) implies that camelid usage at El Palacio consisted of more than meat; specifically, whereas the people of Pacopampa used cervids for meat only, at El Palacio, the use differed between the two camelid species, and both species were used for secondary products.

This variation may also reflect differences in the nature of each site. Notwithstanding differences in the time period, Pacopampa was a ceremonial center and El Palacio a political center. Thus, whereas the people of Pacopampa would gather young, fleshy camelids for use in rituals, the people of El Palacio would use/consume camelids in a more everyday way. Given these differences in site function and socioeconomic backdrop, it seems likely that a number of the specimens at El Palacio were whole or partial carcasses procured from other sites. For example, with Wari dominion extending across a wide area, El Palacio would have been able to procure goods from the south. Relics found at El Palacio include spondylus shells, obsidian, and Wari pottery. The earthenware is made from a dense orange paste not native to the site. Thus, either the completed ware was brought to Cajamarca, or the ingredients were brought there and the ware was later produced there. These relics suggest relations with distant communities. Alongside such relics, the people of El Palacio would have had access to camelids brought to the site in caravans. They may also have acquired ch'arki made in higher regions. The fact that the El Palacio site has also yielded alpaca remains, while the Pacopampa site has not, provides further evidence of connections with the highlands. Another possible explanation is that ch'arki was made in neighboring highlands at an altitude of $4000 \mathrm{~m}$ around the Cajamarca Basin and was transferred to the El Palacio site. With the current data, we cannot determine which explanation is plausible in the present case.

\section{The direction of the cut marks}

At El Palacio, cut marks were found on the neck of the ribs (Figure 13c-1) and on the ventral side of the lumbar vertebral body (Figure 13b-1).

Regarding the reasons for employing the ch'illa method of slaughter, one reason, according to Miller (1979), is that "With this method one does not stain Pachamama, the earth goddess" (Miller, 1979: 30). Another reason is that since the blood collects in the thoracic cavity, it can be efficiently scooped out later (Miller, 1979). After slaughter, the animal is laid on its back for paunching (Miller, 1979). After it is skinned, an incision is made in the abdomen (Miller, 1979). The torso is butchered as follows: the butcher cuts from the sternum through to the costal cartilage and then slices the intercostal muscles by cutting along the median line from the ventral to the dorsal side (Miller, 1979). Finally, the joints connecting the ribs and thoracic vertebrae are removed (Miller, 1979).

The llama butchery the first author observed in Puno proceeded as follows. First, prayers were said to Pachamama. Next, a basin was placed below the neck to catch the blood. The llama was killed by an incision of the neck from the ventral direction. The llama was then laid on its back and skinned. An incision was made in the abdomen and the heart wrenched out. Next, the body was dismembered and the torso segmented. According to the locals, the vertebrae and ribs are cut into pieces suitable for consumption; hence, there is little concern about breaking the bones.

The cut marks on the neck of the ribs (Figure 13c-1) and the ventral side of the lumbar vertebra (Figure 13b-1) at El Palacio indicated that the animal was dismembered from the ventral side while lying on its back, which is consistent with the modern butchering practices observed by the first author. It is possible that the camelids at El Palacio were also dismembered by removing the internal organs from the ventral side and dismembering each part. In this case, the people may have been conscious of ritual considerations such as taking care not to pollute the earth, which has been pointed out in historical records and modern butchering practices.

\section{Conclusions}

Among the camelid specimens of El Palacio, cut marks were observed on all skeletal parts. These cut marks were the result of disjointing bones, skinning, and removing meat, fat, and bone marrow.

Cut marks appeared among the camelid specimens from El Palacio at a frequency of $1.3 \%$. Although this was higher than the frequency among the Pacopampa specimens, it was lower than that among the cervid specimens from Pacopampa. One possible reason for the low frequency is the high 
number of bone fragments, which may explain the appearance of cut marks throughout the skeleton. Another reason may be that husbandry practices emphasized, as they still do today, keeping the camelids alive as long as possible for use as pack animals (in the case of llamas) or as sources of wool (in the case of alpacas).

The presence of cut marks on the ventral sides of the bones was the result of ritualistic considerations in the butchery designed to avoid staining Pachamama, the earth goddess. Under this system, the butcher lays the animal on its back, disembowels it on its ventral side, and then dismembers it.

If ch'arki was indeed consumed in El Palacio, then the residents would have procured it by one method or another from another site along with whole camelids to be consumed as fresh meat.

\section{Acknowledgments}

We would like to express our thanks to Tomohito Nagaoka of Aomori Public University for instructing us in research techniques and thesis writing. We also thank Kazuhiro Uzawa of the University of East Asia for encouraging us in all aspects of our research. We also thank Hitomi Hongo of the Graduate University for Advanced Studies, Yasutake Kato of Saitama University, Yuji Seki of the National Museum of Ethnology, Kinya Inokuchi of Saitama University, and Yutaka Miyake of Tsukuba University for their research guidance, plus Yoshifumi Sato of the National Museum of Ethnology, Megumi Arata of Tenri University, and Nagisa Nakagawa of the National Museum of Ethnology for their support. This study was partially supported by JSPS Kakenhi (19682004, 23682011, 19H01396, 23401040, 23222003, 20H00050, 20H01377) and the Sasakawa Scientific Research Grant from The Japan Science Society (23-119).

\section{Author contributions}

H.S. collected the data and wrote the paper. S.W. excavated the El Palacio site and wrote the part on the materials.

\section{References}

Altamirano Enciso A.J. (1983) Guía osteológica de cérvidos Andinos. Serie investigaciones No. 6. Universidad Nacional Mayor de San Marcos, Lima (in Spanish).

Binford L.R. (1978) Nunamiut Ethnoarchaeology. Academic Press, New York.

Binford L.R. (1981) Bones: Ancient Men and Modern Myths. Academic Press, New York.

Goñalons G.L.M. and Yacobaccio H.D. (2006) The domestication of South American camelids: a view from the South-Central Andes. In: Zeder M.A., Daniel G.B., Emshwiller E., and Smith B.D. (eds.), Documenting Domestication. University of California Press, Berkeley, Los Angeles and London, pp. 228244.

Guaman Poma de Ayala F. (1980) [1615] Nueva corónica y buen gobierno. Tomo II, ed. Franklin Pease G. Y. Biblioteca Ayacucho, Caracas (in Spanish).

Inamura T. (1995) Llama to alpaca: Andes no senjuumin shakai to bokuchiku bunka. Kadensha, Tokyo (in Japanese).

Inamura T. (2007) Kyuutairiku no joushiki wo kutsugaesu Andes bokuchiku no tokusyoku. In: Yamamoto N. (ed.), Andes kouchi. Kyoto University Press, Kyoto, pp. 259-277 (in Japanese).

Kadwell M., Fernandez M., Stanley H.F., Baldi R., Wheeler J.C., Rosadio R., and Bruford M. W. (2001) Genetic analysis reveals the wild ancestors of the llama and the alpaca. Proceedings of the Royal Society of London. Series B, Biological Sciences, 268: 2575-2584.

Kato Y. and Yamauchi S. (2003) Shinpen kachiku hikaku kaibou zusetsu joukan, Yokendo, Tokyo (in Japanese).

Lyman R.L. (1994) Vertebrate Taphonomy. Cambridge Manuals in Archaeology. Cambridge University Press, Cambridge.

Marcus J., Sommer J.D., and Glew C.P. (1999) Fish and mammals in the economy of an ancient Peruvian kingdom. Proceedings of the National Academy of Sciences of the United States of America, 96(11): 6564-6570.

Marín J.C., Zapata B., González B.A., Bonacic C., Wheeler J.C., Casey C., Bruford M., Palma E., Poulin E., Alliende M.A., and Spotorno A.E. (2006) Sistemática, taxonomía y domesticación de alpacas y llamas: nueva evidencia cromosómica y molecular. Revista Chilena de Historia Natural, 80: 121-140 (in Spanish with English summary).

Matsui A. (2008) Fundamentals of Zooarchaeology in Japan. Kyoto University Press, Kyoto (in Japanese).

Miller G.R. (1979) An introduction to the ethnoarchaeology of the Andean camelids. Ph.D. dissertation, University of California, Berkeley.

Miller G.R. and Burger R.L. (1995) Our father the cayman, our dinner the llama: animal utilization at Chavín de Huántar, Peru. American Antiquity, 60: 421-458.

Moore K.M. (1989) Hunting and the origins of herding in Peru. Ph.D. dissertation, University of Michigan, Ann Arbor. https:// deepblue.lib.umich.edu/handle/2027.42/162232

Pacheco Torres V.R., Altamirano E., Alfredo J., and Guerra Porras E.S. (1986) The osteology of South American camelids. Archaeological Research Tools, Vol. 3, trans. Sandefur E. Institute of Archaeology, University of California, Los Angeles.

Pulgar Vidal J. (1987) Geografía del Perú: Las ocho regiones naturales, la regionalización transversal, la microregionalización (noveno editión). PEISA, Lima (in Spanish).

Rosenfeld S.A. (2011) Foodways and sociopolitics in the Wari Empire of Peru, AD 600-900. Ph.D. dissertation, Department of Anthropology, Stanford University, Stanford. https://stacks. stanford.edu/file/druid:kn470yc2748/Rosenfeld_S_Disserta tion\%202011-augmented.pdf

Rosenfeld S.A. (2012) Animal wealth and local power in the Huari Empire. Ñawpa Pacha, 32: 131-164.

Seki Y. (2017) Andes bunmei: Shinden kara yomitoru kenryoku no sekai. Rinsen Book Co., Kyoto (in Japanese).

Shimada M. (1982) Appendix IV: Zooarchaeology of Huacaloma: behavioral and cultural implications. In: Terada K. and Onuki Y. (eds.), Excavations at Huacaloma in the Cajamarca Valley, Peru, 1979. University of Tokyo, Tokyo, pp. 303-336.

Shimada M. (1985) Appendix III: Continuities and changes in patterns of faunal resource utilization: Formative through Cajamarca Periods. In: Terada K. and Onuki Y. (eds.), The Formative Period in the Cajamarca Basin, Peru: Excavations at Huacaloma and Layzón, 1982. University of Tokyo Press, Tokyo, pp. 289-315.

Shipman P. (1981) Applications of scanning electron microscopy to taphonomic problems. Annals of the New York Academy of Sciences, 376: 357-385.

Torres H. (1992) South American Camelids: An Action Plan for their Conservation. IUCN, Gland, Switzerland.

Uzawa K. (2007) Senshi Andes ni okeru rakudaka kachiku no kakusan. In: Intoh M. (ed.), Shigen jinruigaku 07: Seitai shigen to shouchouka. Kobundo, Tokyo, pp. 99-130 (in Japanese).

Uzawa K., Seki Y., and Morales Chocano D. (2021) Ritual consumption and sacrifice of llama (Lama grama) at the Pacopampa site in the Northern Highlands, Peru. Anthropological 
Science, DOI: 10.1537/ase.210411 (in press).

Webster A.D. and Janusek J.W. (2003) Tiwanaku camelids: subsistence, sacrifice, and social reproduction. In: Kolata A. (ed.), Tiwanaku and its Hinterland: Archaeology and Paleoecology of an Andean Civilization, Vol. 2. Urban and Rural Archaeology. Smithsonian Institution Press, Washington DC, pp. 343362.

Wheeler J.C. (1984) On the origin and early development of camelid pastoralism in the Andes. In: Clutton-Brock J. and Grigson C. (eds.), Animals and Archaeology 3: Early Herders and their Flocks. British Archaeological Research International Series 202, BAR Publishing, Oxford, pp. 395-410.

Wing E.S. (1986) Domestication of Andean mammals. In: Vuilleumier F. and Monasterio M. (eds.), High Altitude Tropical Biogeography. Oxford University Press, Oxford, pp. 246-264. 